1 Gurney JW, Goodman LR. Pulmonary edema localized in the right upper lobe accompanying mitral regurgitation. Radiology 1989;171:397-9.

2 Grenon $\mathrm{H}$, Bilodeau S. Pulmonary edema of the right upper obe associated with acute mitral regurgitation. Can Assoc Radiol f 1994;45:97-100.

3 Alarcon J, Guembe P, Miguel ED, et al. Localized right upper lobe edema. Chest 1995;107:274-6.
4 Schnyder PA, Sarraj AM, Duvoisin BE, et al. Pulmonary edema associated with mitral regurgitation: prevalence of predominant involvement of the right upper lobe. $A f R$ 1993;161:33-6.

5 Case records of the Massachusetts General Hospital weekly clinicopathological exercises. N Engl f Med 1995;332: 1566-72.

\title{
Traumatic pseudoaneurysm of the superficial temporal artery
}

\author{
W R Cross, H Nishikawa
}

A 25 year old man presented to the accident and emergency department with a left preauricular mass (fig 1). During an altercation four weeks previously he had received a single kick to his left temple. Although symptom free, he was concerned that a swelling was still present despite resolution of associated bruising. Physical examination displayed a $1 \mathrm{~cm}$ pulsatile mass, anterior to the left ear, which diminished when the superficial temporal artery (STA) was compressed proximally. A diagnosis of aneurysm of the STA secondary to trauma was made. The aneurysm was ligated and resected (fig 2) and the patient recovered without complication. Histopathological examination revealed that the artery was focally dilated and its intima incomplete-hence a false aneurysm or pseudoaneurysm by definition.

Plastic, Hand, and Reconstructive Surgery Unit, St James' University Hospital, Beckett Street, Leeds LS9 7TF W R Cross

H Nishikawa

Correspondence to: Dr Cross, Senior House Officer.

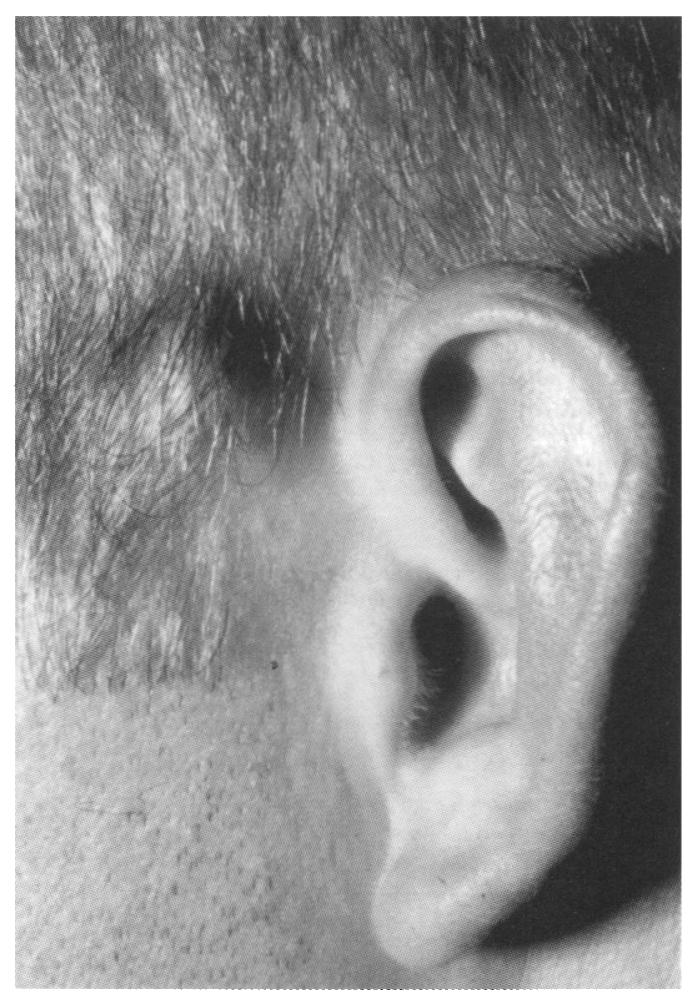

Figure 1 Preauricular mass.
Traumatic STA pseudoaneurysms are rare. Over $80 \%$ occur in men, $75 \%$ are due to blunt trauma, and most patients present within two to six weeks of injury. ${ }^{1}$ In our opinion the diagnosis can be made from a thorough history and examination. Arteriography, duplex ultrasound, and contrast computed tomography have been shown to aid diagnosis in complicated cases. Operative treatment is indicated to prevent rupture from subsequent trauma and to correct the cosmetic defect.

Although rare, all physicians who treat patients with head and facial trauma should be aware of traumatic pseudoaneurysms of the STA.

1 Peick AL, Nichols WK, Curtis JJ, et al. Aneurysms and pseudoaneurysms of the superficial temporal artery caused by trauma. $\mathcal{F}$ Vasc Surg 1988;8:606-10.

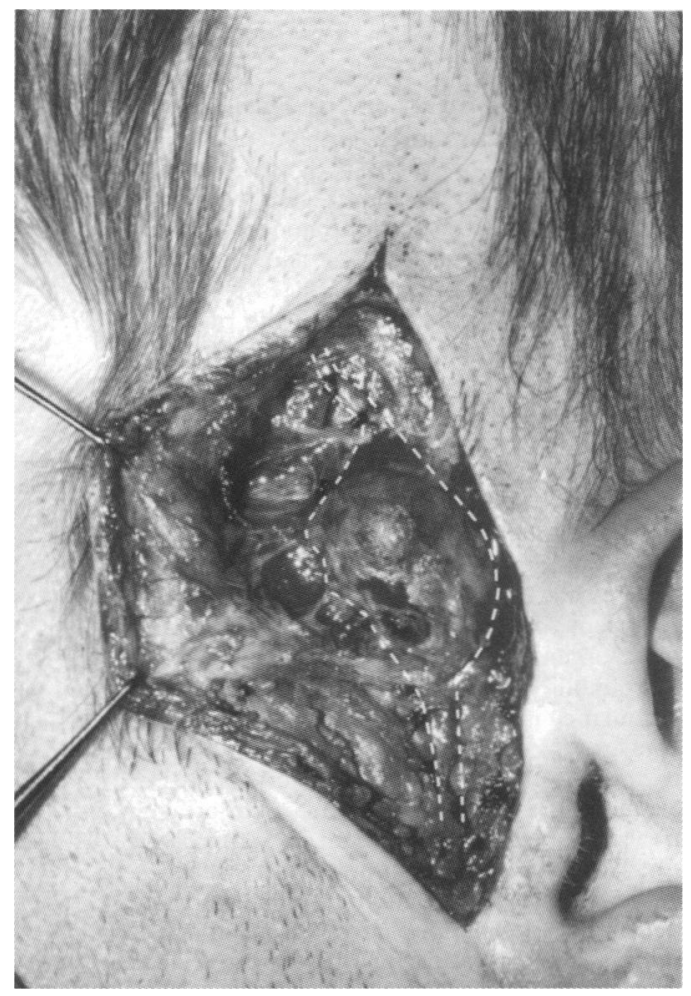

Figure 2 Ligated and resected aneurysm. 